\title{
MOVIMENTOS DO VALE: CORPO E NARRATIVA
}

Carolina Antunes*

RESUMO:

Neste ensaio, enfocando relações entre o eu e o outro, o
local e o global, mostra-se que a cerâmica e os contos
fantásticos do Vale do Jequitinhonha possibilitam a visão-
como processo - da construção identitâria dessa região.
Sofrendo uma ressimbolização na modernidade, essas
manisfestações culturais orais e o próprio Vale são vistos
como objetos culturais, cujo estudo favorece a inscrição de
suas vozes junto às vozes legitimadoras da cultura oficial.

PALAVRAS-CHAVE: cultura popular, narrativa, tradição, identidade, outridade.

A este ensaio subjaz um trabalho de Campo em que foram observadas centenas de peças de cerâmica e ouvidos/gravados dezenas de contos fantásticos. Dentro dessa diversidade, foi feita uma seleção, tendo como ponto de partida o artesanato de cerâmica do Campo Alegre, no município de Turmalina, em diálogo com a cerâmica de outros municípios da região, e onze contos fantásticos, coletados em Turmalina e Araçuaí, municípios situados no Alto e no Médio Jequitinhonha, respectivamente.

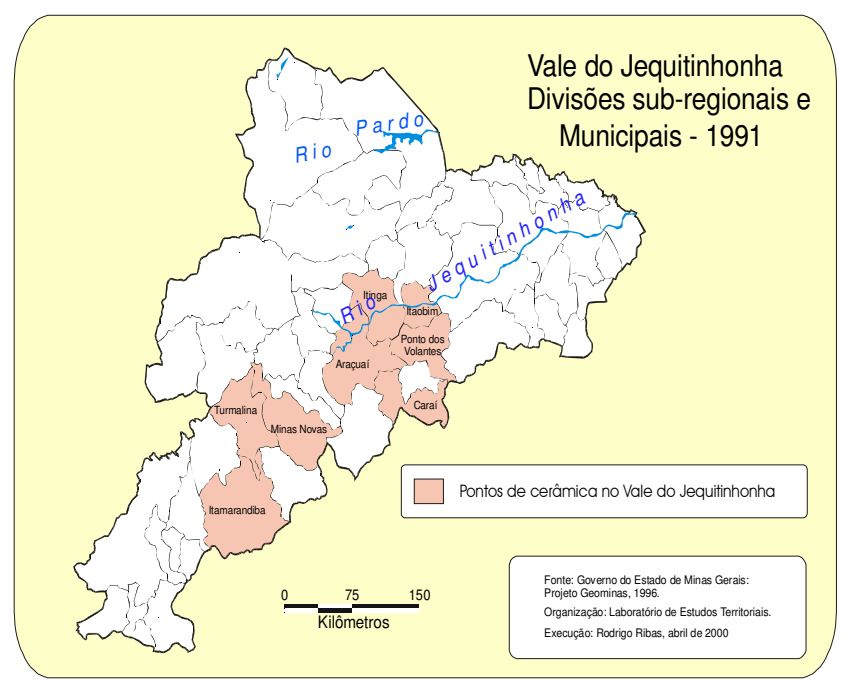

* Doutora em Letras: Estudos Literários (Área de concentração: Literatura Comparada), 2000. 


\section{EM TESE}

Belo Horizonte, v. 5, p. I-305, dez. 2002

Com base em uma leitura do narrador tradicional, de Walter Benjamin; do conceito de outridade, de Octavio Paz e das idéias de polifonia e dialogismo, de Mikhail Bakhtin, os conceitos de cultura popular, narrativa, tradição, identidade, outridade, foram retomados numa perspectiva intertextual, aplicada tanto ao artesanato de cerâmica quanto aos contos fantásticos. Desse modo, os objetos/sujeitos deste trabalho, estudados, de início, isoladamente, só posteriormente foram cotejados em termos de suas semelhanças e diferenças. Assim, no confronto do contexto entre eles, a cerâmica e os contos possibilitam não só a percepção da diferença na perspectiva do aqui/agora, mas também uma visão da construção identitária do Vale do Jequitinhonha, em cujo espaço e em cuja narrativa, essa construção é marcada por trocas interculturais, que se manifestam nas relações sociais.

Estudando, pois, dentro de uma perspectiva social, essas manifestações culturais, ambas tomadas como narrativas orais, busco reconhecer a construção de uma determinada identidade social para o Vale do Jequitinhonha. Essa busca, por mais que a queira completa, é e será sempre lacunar, fragmentária, parcial. Observando a disposição de tais manifestações no tempo, encontra-se, é verdade, um corpo: um corpo com frestas, vazios, que deixam não só ir para a frente, retornando, como também antever o que está mais além. Isso possibilita um saber que admite a incompletude, o vazio e o fragmento como construtores de outros sentidos e de um outro tipo de engajamento: o engajamento com a linguagem.

No corpo narrativo, as relações familiares, as funções sociais exercidas pelas personagens confirmam a linguagem como um espaço de poder no qual quem fala e, de acordo como fala, marca o lugar idelógico em que o discurso é pronunciado, pois a palavra é uma força real, que gera os fatos e as coisas. Ao mesmo tempo que isso acontece, o sujeito que narra também se constitui com marcas do outro, de modo que um traço coletivo subjaz à linguagem, um espaço de contradições em que o desejo de controle e o de relação, não se constituindo como categorias estanques, sintetizam um desejo de ser da narrativa, na qual se estruturam discursos culturais em seus vários aspectos.

Nesse corpo narrativo, personagens, situações, tempos e espaços diferenciados e determinados concretizam-se, figurativa e tematicamente, nas formas, nos tipos, 
nas cores que traduzem o espaço geográfico do narrador, onde a realidade exterior, visível, sensível, associada às realidades criadas pelo discurso, fornece a substância constitutiva do processo de narrar. Assim, a bandeja com bule e xícaras, por exemplo, está efetivamente presente não só no mundo natural, concreto, cotidiano da vida, como também no universo criado pelo discurso social, abstrato, marcado pela cordialidade familiar. A mulher-jerimum, da mesma forma, constituindo-se de duas imagens de seres presentes nesse mundo - a mulher e o jerimum - resulta na peça fantasmática que ganha expressão na realidade criada pelas figuras antropomorfas e zoomorfas, do mesmo modo que, na narrativa folclórica, por exemplo, o saci ganha status de ser ou que, no conto Santa Isabele, a transformação do pão em flor ou em Os treis rapaz, a transformação da maçã em moça bonita, tem existência e sentido na realidade do conto maravilhoso ou fantástico.

Possibilitando uma leitura do real sob os dois pólos/aspectos em questão, o corpo narrativo produz um efeito de realidade e, por isso, representa um mundo, cria dele uma imagem com seus seres, seus acontecimentos etc. Nesse mundo, pode-se dizer, as figuras, as peças, as personagens, as situações, com base na relação de significado que mantêm entre si, articulam-se de tal maneira que o sentido de uma peça ou de uma situação, ou de uma de suas partes, é definido pela relação estabelecida com outras peças ou outras situações com as demais partes do todo, evidenciando que o sentido do todo não é uma mera soma das partes; antes, é produto de múltiplas relações que se estabelecem entre elas.

Nesse jogo de relações, o indivíduo que trabalha o barro e o que conta histórias instituem-se como o tradicional narrador benjaminiano, cujo senso prático, qualidade de muitos narradores, transparece em seu texto através de uma pluralidade originada de formas, cores, cenas, tipos os mais diversos. Narrador que, estando efetivamente presente em seu mundo, expõe-se e submete-se a suas situações e a seus acontecimentos, registrando-o em suas criações, mostrando-se nelas no tempo que passa e mesclando as vozes da tradição às vozes do mundo moderno.

Objetos de utilidade doméstica e de ornamentação, animais e vegetais, homens e mulheres, jovens e velhos desempenham um papel de extrema relevância na constituição desse corpo narrativo, no qual o narrador, como ser social, projeta 


\section{EM TESE}

Belo Horizonte, v. 5, p. I-305, dez. 2002

seus desejos e seu inconsciente, ao mesmo tempo que deleneia um tempo e um espaço de aparência contraditória. Nessa narrativa polivalente, movimentam-se, dialogicamente, a tradição e a modernidade, o rural e o urbano, elementos que, simultaneamente, transformam os corpos daqueles que narram em guardiães do tempo e do espaço paradoxais. Aí os objetos e as situações criadas acabam por perder, um pouco e gradativamente, o vínculo com o passado, que se manifesta como reminiscência, pois seu sentido só se efetiva a posteriori e sua realidade objetiva só é resgatada parcialmente, uma vez que nenhuma experiência é vivenciada isoladamente. Novas ligações vão sendo constituídas e, nelas, o passado, resultando de uma complexa elaboração e se reconstruindo no momento da elaboração do texto, torna-se presente como como via de mão dupla.

0 artesanato da cerâmica e os contos fastásticos esboçam, pois, o quadro social e com ele um texto sobre o Vale é urdido. Texto cuja mobilidade do enunciado caracteriza a enunciação e o registro das histórias; texto cuja mobilidade pode ser observada nas figuras de cerâmica, denunciando o imbricamento entre a modernidade e a tradição, através da convivência paradoxal entre o desejo da modernidade e a resistência simbólica que transparece no ato de moldar o barro e contar histórias. Por isso, esse ato resgata um grupo minoritário, inserindo-o na história e, conseqüentemente, quebrando a continuidade da mesma, refaz e amplia a memória da região. Nesse sentido, desconstruindo, a memória é operadora da diferença que participa da noção de identidade como lugar de construção. Daí se poder dizer, conforme Canclini (1996: 64), que

A separação entre grupos hegemônicos e subalternos já não se apresenta principalmente como oposição entre o nativo e o importado, ou entre 0 tradicional e o moderno, mas como adesão diferencial a subsistemas culturais de diversa complexidade e capacidade e de inovação...

Esse autor diz ainda que "a identidade surge, na atual concepção da ciências sociais (...) como uma construção imaginária que se narra..." (p. 124). Dessa forma, estudando o artesanato de cerâmica e os contos fantásticos e observando a formação de referentes identitários do Vale do Jequitinhonha nos contextos da tradição e da modernidade, notei que, nesses contextos, proliferam os repertórios textuais e iconográficos gerados pelos meios eletrônicos, que colaboram, fortemente, com a globalização dos costumes, da vida, do mundo, interferindo, portanto, nas manifestações daquele. 
Justifica-se, então, a minha preocupação em entender essa construção sem imputar-1he um caráter único, mas considerando-a como múltipla e vária, compreendendo as manifestações culturais em pauta dentro de uma perspectiva cultural, sem fatalismos e determinações. Nessas manifestações, o eu narrador se mostra capaz de substituir o que perdeu por aquilo que ganhou, (re)fazendo suas relações com o mundo exterior e construindo um corpo que se encontra na própria constituição do social. É, pois, nas representações que um povo faz de seu estar no mundo, que ele, em interação com o outro, produz sua identidade. E este é o processo literal e metaforicamente constuído pela artesã de cerâmica e pelo contador de histórias.

Na construção desse corpo cultural, a recorrência a determinados temas - o mundo do narrador, o narrador e o outro, as metamorfoses, representações da mulher - constrói-se pela oralidade das fontes que, se de um lado se marca pela exclusão, de outro, se marca pela resistência. Esses temas foram estudados com base nas idéias de estudiosos da oralidade, reforçados por Mikhail Bakhitin e outros, constituindo, de acordo com Canclini (1996:25),

(...) uma esfera pública pebléia, informal, organizada por meio de comunicações orais e visuais mais do que escritas (...), foros onde se desenvolvem redes de inrtercâmbio de informação e aprendizagem da cidadania em relação aos meios de comunicação de massa contemporâneos...

Assim sendo, refletir sobre o artesanato de cerâmica e sobre os contos fantásticos, práticas emergentes não consagradas pela ordem jurídica, fez-me exercitar a cidadania e encarar esse exercício como uma estratégia política que me leva a um melhor entendimento do lugar dessas práticas na contemporaneidade. Por isso, elas não representaram - para mim - apenas um caminho de acesso às emoções, mas também uma possibilidade de acesso a um tipo de conhecimento, pois que foram vistas como formando um corpo cultural, corpo histórico, um campo articulado de elementos relevantes que me impeliram/impelem a repensar minhas verdades, a reciclar minha postura intelectual, a conviver com outros paradigmas socioculturais.

Este ensaio, que pode ser visto como uma trilha que dá a conhecer o texto-bosque - Vale do Jequitinhonha -, coloca em relevância o outro, que é múltiplo e vário, como é múltipla e vária essa região, ou seja, o mundo do narrador; como confirma a pluralidade de relações, de encontros/desencontros levantados e vividos 


\section{EM TESE}

Belo Horizonte, v. 5, p. I-305, dez. 2002

pelo narrador e pelo outro; como se pode constatar da polifonia e da abertura para o outro, presentes nas personificações e metamorfoses, tanto do artesanato de cerâmica quanto dos contos fantásticos; como se pode ver do embate, do aparente desencontro entre o homem e a mulher, observado nas representações da mulher.

Priorizar o outro, além de me propiciar um conhecimento mais ampliado da região em pauta fez com que eu me colocasse no lugar dele e/ou dos inúmeros outros, que entraram na constituição da narrativa desse conjunto global que é o Vale do Jequitinhonha. Desse modo, se, de um 1ado, pude perceber suas carências psicossociais, aliadas a carências de toda ordem; de outro lado, pude concordar com estudiosos dessa região no que se refere à vitalidade de sua cultura popular. Cultura que pode ser considerada como uma das maiores riquezas potenciais do Vale do Jequitinhonha.

Essa percepção me possibilitou considerar a escrita deste ensaio como um instigante trabalho no sentido de valorização da cidadania, de um maior entendimento e valorização do humanismo e da democracia das idéias. Escrevendo-o, pude urdir o tecido e construir a rede - Vale do Jequitinhonha - como um texto-bosque, que eu imagino e que eu narro.

ABSTRACT :

This essay aims at discussing the traditional pottery and folk tales characterizing the Valley of the Jequitinhonha River, in Minas Gerais, and their significance in the creation of a cultural identity. After a process of resymbolization, or re-signification, these traditional artifacts and the Valley itself are viewed as cultural objects, whose investigation contributes to the legitimization of these marginalized voices and to their inscription in the official culture and the academic discourse.

KEY WORDS: popular culture, narrative, tradition, identity, otherness. 
BACZK0, Bronislaw. Les imaginaires sociaux. Mémoirs et spoirs collectifs. Paris: Payot, 1984.

BAKHTIN, Mikhail. Problemas da poética de Dostoiévski. Trad. Paulo Bezerra. Rio de Janeiro: Forense Universitária, 1981.

BENJAMIN, Walter. Magia e técnica, arte e politica. Ensaios sobre literatura e história da cultura. Trad. Paulo Sérgio Rouanet. São Paulo: Brasiliense, 1987.

BHABHA, Homi K. O local da cultura. Trad. Myriam Ávila et al. Belo Horizonte: Editora UFMG, 1998.

CANCLInI, Néstor García. Consumidores e cidadãos. Trad. Maurício Santana Dias, Javier Rapp. Rio de Janeiro: Ed. UFRJ, 1996.

CHAUÍ, Marilena. Conformismo e resistência: aspectos da cultura popular no Brasil. São Paulo: Brasiliense, 1987.

LE GOFF, Jacques. A história nova. Trad. Eduardo Brandão. São Paulo: Martins Fontes, 1983.

MARQUES, Reinaldo Martiniano. Entre o global e o local: cultura popular do Vale do Jequitinhonha e reciclagens culturais. In: DALMASSO, Maria Tereza et al. (Org.). Discursos da tradición y contemporaneidad. Córdoba: Centro de Estudios Avanzados (U.N.C.), 1998, p.97-107. MATOS, Sônia Missagia. Artefatos de gênero na arte do barro. UNICAMP, Campinas, 1998. (Tese de Doutorado)

PAZ, Octavio. Convergências: ensaios sobre arte e literatura. Trad. Moacir Werneck de Castro. Rio de Janeiro: Rocco, 1991. 
Belo Horizonte, v. 5, p. I-305, dez. 2002

QUEIR0Z, Sônia. A voz de Paul Zumthor. Minas Gerais, Belo Horizonte, n.43, nov. 1998. p.18-21. Suplemento Literário.

SARL0, Beatriz. Cenas da vida pós-moderna: intelectuais, arte e video-cultura na Argentina. Trad. Sérgio Alcides. Rio de Janeiro: Ed. UFRS, 1997.

SILVA, Napoleão III Medeiros. Vale do Jequitinhonha: incorporação e transformações estruturais. Belo Horizonte: CEPEPLAR/UFMG, 1987.

SOJA, Edward. Geografias pós-modernas. Trad. Vera Ribeiro. Rio de Janeiro: Jorge Zahar, 1993.

STRINATI, Dominic. Cultura popular: uma introdução. Trad. Carlos Szlak. São Paulo: Hidra, 1999.

WALTY, Ivete Lara Camargos. Escrita e corpo; faces femininas da América Latina em 0ctavio Paz. In: MACIEL, Maria Esther (Org.). A palavra inquieta: homenagem a Octavio Paz. Belo Horizonte: Autêntica: Memorial da América Latina, 1999. p.137-148.

ZUMTHOR, Paul. A letra e a voz. Trad. Amália Pinheiro e Jerusa Pires Ferreira. São Paulo: Companhia das Letras, 1993. 